\title{
NUMERICAL RESEARCH ON DYNAMICAL BEHAVIOUR OF ALLOY TITANIUM TC4
}

\author{
J.S. ZHU and Z.J. TU \\ Institute of Applied Physics and Computational Mathematics, \\ P.O. box 8009, Beijing, China
}

\section{RESUME :}

On propose un modèle NAG-FRAG simplifié et implanté dans APHEMP, un hydrocode bidimensionnel élasto-plastique, pour simuler les résultats expérimentaux d'essais d'impact de plaques de tungstène contre des cibles en titane, à différentes vitesses d'impact. Après avoir brièvement décrit le modèle, on présente une comparaison entre les longueurs de bandes de cisaillement obtenues par l'expérience et par le calcul.

Abstract-A simplified NAG-FRAG model is proposed and added to APHEMP, two-dimensional elastic-plastic hydrodynamic code, to simulate experimental results of titanium plates impacted by tungsten projectiles with varied speeds. The simplifiers are described briefly and calculating lengths of shear bands are compared experimentally in this paper.

\section{1.-Introduction.}

A recent critical review of shear band deformation in metal at high strain rates has been provided by Timothy ${ }^{1}$. Microstructural and fracture studies of impacted plates of $\mathrm{Ti}-6 \mathrm{Al}-4 \mathrm{~V}$ alloy have been reported by many authors ${ }^{2,3,4}$. Holt and others studied impact bahaviour of $\mathrm{Ti}-6 \mathrm{~A} 1-4 \mathrm{~V}$ alloy for the conditions in which the plug of disk material is pushed only partway through the disk ${ }^{5}$. Seaman, et al. developed and used a computational shear band model to predict the fragmentation response of explosively-loaded cylinders and munitions of HF-1 and Armco iron ${ }^{6}$.

Experimental results of alloy titanium TC4 plates impacted by tungsten projectiles with varied speed have been given by $\mathrm{Wan}$, et $\mathrm{al}^{7}$. The results show the formation and development of shear bands. In $10 \mathrm{~mm}$ target plates of titanium, shear bands begin to build up when speed of tungsten projectile is about $80 \mathrm{~m} / \mathrm{s}$, as projectile speed increases, the length of shear band grows until the band penetrates the target plate at a speed of about $240 \mathrm{~m} / \mathrm{s}$. Near this situation shear instability occurs.

APHEMP code is developed in our institute according to HEMP version. For calculating the shear bands, some simplifications on Nucleation and Growth and Fragmentation (NAG-FRAG) model are made to surmount the lack of microstructure parameters for alloy titanium. The simplified NAG-FRAG model is added to APHEMP code as a subroutine and used to calculate the impact problem.

\section{2.-Simplified shear band model:}

The NAG-FRAG model includes many physical processes. They are nucleation of shear bands, growth of the bands, coalescence to form fragments, and relaxation of the stresses in 
accordance with the growth of damage. Each physical process contains some material parameters, which must be determined by experiments. To overcome the lack of experimental data, we made some simplifications on NAG-FRAG model as following. Only simplifications are described here, the details of the model can be found in reference 6.

\section{1)Nucleation}

Here a nucleation rate function is proposed to account for the observed relationships to plastic shear strain and yield strength and to provide an orientation dependence for the shear band process. The major assumption in the following proposed expression is that the nucleation rate in a direction is proportional to the plastic shear strain in the same direction.

$$
\dot{N}_{i}=\frac{d N_{1}}{d t}=C_{n} F_{i}\left(\frac{1}{E_{c r}} \frac{d E^{p}}{d t}\right)^{2} \frac{d \varepsilon_{i}^{p s}}{d t}
$$

where $E_{c r}$ is a critical energy, taken to be the melt energy; $\mathrm{dE}^{\mathrm{D}} / \mathrm{dt}$ is the rate of increase of plastic strain energy; $\mathrm{Ni}$ is the number of shear bands per unit volume in the $\mathrm{i}$ direction; and $\varepsilon_{i}^{p s}$ is the plastic shear strain in the same direction, here six directions are proposed. $\mathrm{Cn}$ is a coefficient with the unit of time squared, and $\mathrm{Fi}$ is a factor representing the fraction of solid angle assigned to the $\mathrm{i}$ direction. Shear bands may appear in many directions, we have chosen six specific directions to represent the continuum of all directions. The directions provided are for bands normal to three perpendicular coordinate directions and for three more at $45^{\circ}$ to the first three. Each of the first three direction represents two points on the unit sphere whereas each of the $45^{\circ}$ directions represent four points. Therefore, it seemed reasonable to weigh the six points with factors,

\section{$F_{i}=1 / 9,1 / 9,1 / 9,2 / 9,2 / 9,2 / 9$ respectively.}

For each orientation there is a set of size groups consisting of a number of bands per unit volume $\mathrm{Nr}$ with a radius $\mathrm{R}$. Initially these size groups represent the continuous distribution

$$
N_{8}=N_{0} \exp \left(-R / R_{n}\right)
$$

where $\mathrm{Ng}$ is the number of bands with a radius greater than $R$.

$\mathrm{N}_{0}$ is the total number.

$R_{n}$ is a nucleation size parameter.

Not using the set of size groups, we keep using continuous distribution, and define Nir as the number of shear bands per unit volume in $i$ direction with radiuses in unit $R$ interval. According to equations (1) and (2) $\Delta \mathrm{N}_{\mathrm{ir}}$, the increment of $\mathrm{N}_{\mathrm{ir}}$ produced by nucleation in one time cycle $\Delta \mathrm{t}$, can be expressed as

$$
\begin{aligned}
& \Delta N_{i r}=\frac{\dot{N}_{i} \Delta t}{R_{n}} \exp \left(-\frac{R}{R_{n}}\right) \\
& =\frac{\Delta N_{1}}{R_{n}} \exp \left(-\frac{R}{R_{n}}\right)
\end{aligned}
$$

where $\Delta N_{i}$ is the increment of the number of nucleation in timecycle $\Delta t$.

\section{2)Growth}

The growth of a shear band refers to the increase in radius $\mathrm{R}$ of the slipped area. Follow- 
ing Seaman, et $a l^{6}$, we have assumed that the speed of the shear band is proportional both to its radius and to the plastic shear strain rate; that is

$$
\frac{d R}{d t}=C\left[\frac{d \varepsilon_{t}^{p s}}{d t} R\right]
$$

Where $\mathrm{C}$ is a growth coefficient; $\mathrm{d} \varepsilon_{\mathrm{i}}^{\mathrm{ps}} / \mathrm{dt}$ is the plastic shear strain rate in $\mathrm{i}$-th direction; and $R$ is the radius. Integrating equation(4), We get a relation between $R$ and $\varepsilon_{i}^{\text {ps }}$

$$
\frac{R}{R_{0}}=\exp \left[C\left(\varepsilon_{i}^{p s}-\varepsilon_{10}^{p s}\right)\right]
$$

Where $R_{0}$ is the radius of shear band at the moment of nucleation; $\varepsilon_{\mathrm{io}}^{\mathrm{ps}}$ is the plastic shear strain at the same moment.

The total increment of $\mathrm{N}_{\mathrm{ir}}$ should be added by the increment produced by growth process, then according to equation(5), the $N_{i r}$ at $n$-th time cycle after first nucleation time is

$$
\begin{aligned}
& N_{i n}=\frac{\Delta N_{i, n}}{R_{n}} \exp \left(-\frac{R}{R_{n}}\right)+\frac{\Delta N_{i, n-1}}{R_{n} \exp \left[C\left(\varepsilon_{i, n}-\varepsilon_{i, n-1}\right)\right]} \exp \left\{-\frac{R}{R_{n} \exp \left[C\left(\varepsilon_{i, n}-\varepsilon_{i, n-1}\right)\right]}\right\} \\
& +\cdots+\frac{\Delta N_{i, 1}}{R_{n} \exp \left[C\left(\varepsilon_{i, n}-\varepsilon_{i, 1}\right)\right]} \exp \left\{-\frac{R}{R_{n} \exp \left[C\left(\varepsilon_{i, n}-\varepsilon_{i, 1}\right)\right]}\right\}
\end{aligned}
$$

for simplicity, we omitted the superscripts ps. Here subscript $n$ express the values at different time cycles. For any constant $A$ there is

$$
\int_{0}^{\infty} \frac{1}{A} \exp \left(-\frac{R}{A}\right) d R=1
$$

The total number of shear bands is

$$
N_{i}=\int_{0}^{\infty} N_{i r} d R=\sum_{n=1}^{\infty} \Delta N_{i, n}
$$

That is the sum of the number of nucleation at each $\Delta t$.

\section{3)Damage}

Following Seaman, et al., the quantity $\mathrm{T}_{\mathrm{f}} \beta \gamma^{3} \Sigma \mathrm{N}_{\mathrm{ir}} \mathrm{R}_{\mathrm{r}}^{3}$ is a measure of the damage associated with the bands in the $i-$ th orientation. Here $T_{f}$ is a dimensionless volume factor about $4 \pi / 3, \beta$ is the ratio of numbers of fragments and numbers of shear bands. It is about $1 / 3 \sim$ $1 / 4$. The fragment sizes are related to the band sizes through the factor $\gamma, \gamma$ is approximately equal to 1 . Then

$$
\mathrm{K}=\mathrm{T}_{\mathrm{f}} \beta \gamma^{3}=0.33 \sim 0.44
$$


If we use continuous contribution, damage $D_{i}$ has

$$
D_{1}=K \sum_{r} N_{t r} R_{r}^{3}=K \int_{0}^{\infty} N_{t r} R^{3} d R
$$

By using formula (6) and

$$
\begin{aligned}
& \int_{0}^{\infty} \frac{R^{3}}{A} \exp \left(-\frac{R}{A}\right) d R=A^{3} \int_{0}^{\infty} x^{3} \exp (-x) d x \\
& =A^{3} \Gamma(3+1)=(3 !) A^{3}=6 A^{3}
\end{aligned}
$$

(here $x=\frac{R}{R}$ ) we get

$$
\begin{aligned}
& D_{i, n}=6 R_{n}^{3} K\left\{\Delta N_{i, n}+\Delta N_{i, n-1} \exp \left[3 C\left(\varepsilon_{i, n}-\varepsilon_{i, n-1}\right)\right]\right. \\
& \left.+\cdots+\triangle N_{i, 1} \exp \left[3 C\left(\varepsilon_{i, n}-\varepsilon_{i, 1}\right)\right]\right\}
\end{aligned}
$$

Equation (10) can be rewritten as following, more suitable to program

$$
\begin{aligned}
& D_{i, 1}=6 R_{n}^{3} K \triangle N_{i, 1}=6 R_{n}^{3} K M_{1}, \quad M_{1}=\triangle N_{i, 1} \\
& D_{i, 2}=6 R_{n}^{3} K\left\{\triangle N_{i, 2}+M_{1} \exp \left[3 C\left(\varepsilon_{i, 2}-\varepsilon_{i, 1}\right)\right]\right\} \\
& =6 R_{n}^{3} K M_{2} \\
& M_{2}=\triangle N_{i, 2}+M_{1} \exp \left[3 C\left(\varepsilon_{i, 2}-\varepsilon_{i, 1}\right)\right] \\
& \ldots \ldots \\
& D_{i, n}=6 R_{n}^{3} K\left\{\triangle N_{i, n}+M_{n-1} \exp \left[3 C\left(\varepsilon_{i, n}-\varepsilon_{i, n-1}\right)\right]\right\} \\
& =6 R_{n}^{3} K M_{n} \\
& M_{n}=\triangle N_{i, n}+M_{n-1} \exp \left[3 C\left(\varepsilon_{i, n}-\varepsilon_{i, n-1}\right)\right]
\end{aligned}
$$

The total damage is the sum of damages in six directions

$$
D_{n}=\sum_{i=1}^{6} D_{i, n}
$$

According to equations (1) and(3), $\mathrm{D}_{\mathrm{i}, \mathrm{n}}$ have a factor $6 C_{n} R_{n}^{3} K\left(\frac{1}{E_{c r}}\right)^{2}$, which remains constant in calculation. We only calculate quantities $\frac{D_{i, n}}{6 C_{n} R_{n}^{3} K\left(\frac{1}{E_{e r}}\right)^{2}}$ and then $\frac{D_{n}}{6 C_{n} R_{n}^{3} K\left(\frac{1}{E_{c r}}\right)^{2}}$. To simulate the shear band, slide line is used, when $\mathrm{D}_{\mathrm{n}}>\mathrm{D}^{*}$, slide starts 
along slide line. This slide line indicate the location of shear band.

3.-Results and Discussions.

Simplified NAG-FRAG model mentioned above is added to two-dimensional elastic-plastic hydrodynamic code APHEMP to simulate the shear bands in alloy titanium plate impacted by tungsten projectile. The titanium plate is $10 \mathrm{~mm}$ in thickness. The tungsten projectile has a diameter of $8 \mathrm{~mm}$, a length of $8 \mathrm{~mm}$. The speed of projectiles range from $80 \mathrm{~m} / \mathrm{s}$ to over $300 \mathrm{~m} / \mathrm{s}$. It is found that shear band penetrates the plate at a speed of about $240 \mathrm{~m} / \mathrm{s}$ and shear instability occurs. The thickness of shear bands is about $2-20 \mu \mathrm{m}$. To simulate such a thin layer would be very difficult if ordinary elastic-plastic hydrodynamic code were used. So NAG-FRAG model is used, which consider microcrack properties as a similar of constitutive relation of material.

Table 1. The lengths of shear bands $L$ and impact speeds of projectiles $U$

$\begin{array}{lrrrrrr}\mathrm{U}(\mathrm{m} / \mathrm{s}) & 150 & 200 & 230 & 240 & 250 & 270 \\ \mathrm{~L}(\mathrm{~mm}) & 0 & 2 & 7 & 9 & 10 & 10\end{array}$

Calculation results for $10 \mathrm{~mm}$ thickness plate with different projectile speeds are shown in table 1. Figure 1. shows the comparison between experiments and calculations. A shear instability is found near the situation of $U=240 \mathrm{~m} / \mathrm{s}$ both in experiment and in calculation. Experiments also show small shear bands (shorter than $1 \mathrm{~mm}$.) in the plates when projectile speeds range in $80 \mathrm{~m} / \mathrm{s}-150 \mathrm{~m} / \mathrm{s}$. Calculations did not give this results, for numerical mesh is comparative large(about $1 \mathrm{~mm}$ ). Figure 2. shows the increase of the depths of craters with the increase of projectile speeds. When speeds are less than $250 \mathrm{~m} / \mathrm{s}$, simulation is satisfied, but the growth of crater is slower than that in experiments when speeds are greater than $250 \mathrm{~m} / \mathrm{s}$

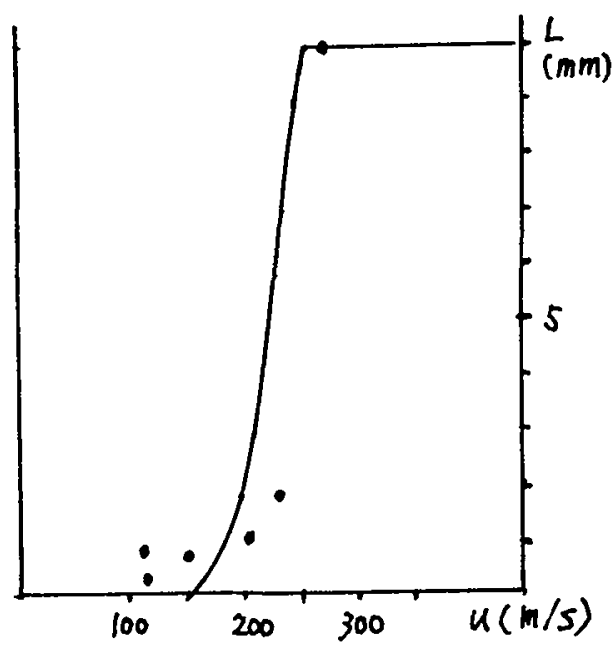

Figure 1. The lengths of shear bands. Comparison between Calculations and experiments. 


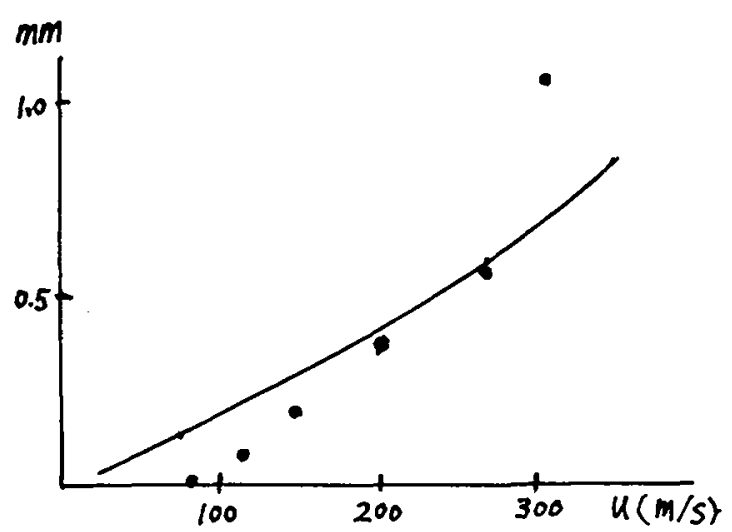

Figure 2. The depths of craters. Comparison between Calculations and experiments.

Numerical simulation of high strain-rate shear band formation is a difficult and complicated problem. Here is only a preliminary approach, trying to use a simple model with fewer parameters to simulate the main properties. It can be predicted that some more details would be unsatisfied.

\section{References}

1. S.P.Timothy, Acta Metall. 35, 1987, 301-306.

2. R.L.Woodward, Metall. Trans. 10A, 1979, 569-573.

3. Y.Me-Bar and D.Schechtman, Mater. Sci. and Eng. 58, 1983, 181-188.

4. M.A. Meyers and H.R.Pak, Acta Metall. 34, 1986, 2493-2499.

5. W.H.Holt, W,Mock, JR., W.G. Soper and C.S.Coffey, Shck compression of condensed matter, 1989, 915-918.

6. D.C.Erlich, L.Seaman, D.A.Shockey, and D.R.Curran, AD-A084029, 1980.

7. Wan Yan-Ping, et al, "Experimental research on dynamical behaviour of alloy titanium TC4" private communication. 